\title{
Is There any Relationship Between Granulomatous Mastitis and Seasons? An Analysis of Seasonal Frequency, Clinical, and Radiologic Findings
}

\author{
Leyla Tekin ${ }^{1}$ (D), Funda Dinç Elibol' ${ }^{2}$ (1) \\ ${ }^{1}$ Department of Pathology, Muğla Sttkı Koçman University Faculty of Medicine, Muğla, Turkey \\ ${ }^{2}$ Department of Radiology, Muğla Sıtkı Koçman University Faculty of Medicine, Muğla, Turkey
}

\begin{abstract}
Objective: Idiopathic granulomatous mastitis (IGM) is a rare, resistant, and recurrent benign disease of the breast. IGM can be clinically and radiologically confused with breast carcinoma, and core needle biopsy is needed to diagnose. The etiology and pathogenesis of IGM have not been fully explained. This premenopausal disease may be associated with pregnancy, breastfeeding, autoimmune processes, inflammation, and oral contraceptives. However, there is no study on whether there is a seasonal relationship.

Materials and Methods: From January 2015 to January 2020, the seasonal relationship of IGM was evaluated in 37 females aged between 25-49. Results: Although all cases were distributed between September and May, there was no statistically significant result in the relationship with the season. US is the main modality in the diagnosis of this condition which only provides an accurate pre-diagnosis approach with the typical USG appearance features. Some MRI features may help us to distinguish IGM from breast malignities.

Conclusion: IGM is a rare chronic non-specific inflammatory lesion of the breast, which can be confused with benign and malignant breast diseases in both clinical and radiologic aspects. To understand the etiology of this condition better, the seasonal connection needs to be evaluated in larger patient groups.
\end{abstract}

Keywords: Granulomatous, mastitis, radiological findings

Cite this article as: Tekin L, Dinç Elibol F. Is There any Relationship Between Granulomatous Mastitis and Seasons? An Analysis of Seasonal Frequency, Clinical, and Radiologic Findings. Eur J Breast Health 2020; 16(4): 235-243.

\section{Introduction}

Idiopathic granulomatous mastitis (IGM) is a rare benign inflammatory breast entity characterized by lobulocentric granulomas (1). IGM has a persistent or recurrent disease course and affects premenopausal women with a history of lactation. The clinical and radiologic features of IGM are very similar to those of breast carcinoma. The most common clinical manifestation is a unilateral, tender, painful, extra-areolar breast lump $(2,3)$. Although ethnic predisposition has not been proven precisely, the high prevalence of IGM has been observed in certain racial populations $(4,5)$. It may be confused with other breast lesions that have radiologically or histologically similar features to IGM. Lesions of similar characteristics include breast cancer (BC), infective mastitis, foreign body injection granulomas, mammary duct ectasia, diabetic fibrous mastopathy, and systemic granulomatous processes (6).

Mainly ultrasonography (US) and mammography (MG), and to a lesser extent, magnetic resonance imaging (MRI), are used for the diagnosis of IGM $(7,8)$. Imaging findings of this condition have a wide spectrum between benign and malignant features $(8,9)$. A coreneedle biopsy is necessary to differentiate IGM from BC and other benign inflammatory breast lesions. Patients with IGM have excellent prognosis when they are appropriately treated with oral steroids or second-line immunosuppressive and prolactin-lowering medications. Surgical treatment may be an option for patients who fail drug therapy (6).

The etiology and pathogenesis of IGM remain unclear. An association with pregnancy, lactation, local autoimmune processes, infection, hyperprolactinemia, and chemical reaction induced by oral contraceptive pills has been reported in the literature (10, 11). To our knowledge, there are no studies about the seasonal relationship with IGM in the literature. We have observed that these patients were successive at certain times and that we encountered the diagnosis of IGM more frequently at certain times of the year. Accordingly, the current study aimed to investigate if there was a seasonal frequency in this condition. In addition, etiologic factors and radiologic findings were also reviewed. 


\section{Materials and Methods}

\section{Patients}

The patients included in the present study were 37 women aged 25-59 years who underwent core breast biopsy in our hospital from January 2015 to January 2020. The individual medical history of all patients, including age, smoking, pregnancy, parity, lactation, delivery, family history of breast cancer, oral contraceptive was reviewed. The clinical manifestations, including mass, nipple retraction, galactorrhea, abscess formation, presence of a fistula, peau d'orange, pain, and enlargement of ipsilateral axillary lymph nodes, were all considered. Ultrasonography (USG), mammography, and MRI were performed selectively, depending on the symptomology and age of the patient. The diagnosis was made through a core-needle biopsy in all patients using a 14-G needle. The date of the core-needle biopsy was considered as the date of diagnosis of the disease because information about how long the symptoms have been present in patients is often absent in our records and the retrospective history evaluations for patients are inconsistent. Therefore, in the evaluation of monthly and seasonal frequencies, the date of the biopsy was used.

\section{Histopathologic evaluation}

Hematoxylin and eosin-stained paraffin histologic sections were evaluated in detail. IGM was defined as 'perilobular granulomatous inflammation, accompanied by infiltration centered on lobules with lymphocytes, plasma cells, epithelioid histiocytes, multinucleated giant cells, and neutrophils with or without intralobular micro abscess formation (Figure 1). Tuberculosis mastitis was excluded using polymerase chain reaction or Ziehl-Neelsen staining for all cases.

\section{Radiologic evaluation}

The imaging modalities used in diagnosis, and the imaging features of lesions in each modality were noted. Also, if preliminary diagnosis or suspicion of IGM was reported in radiology reports, it was recorded. Lesions were classified in accordance with the American College of Radiology Breast Imaging Reporting and Data System (BI-RADS) Atlas $5^{\text {th }}$ edition (12). The frequencies of quadrant and retroareolar involvement was noted. Lymph node status was also assessed. USG examinations of bilateral breast and axilla were performed using a 7-12-MHz probe (Toshiba Aplio 500, Toshiba Medical System Corporation, Tokyo, Japan). Mammography examination was performed in standard craniocaudal and mediolateral oblique positions (Giotto Tomo, IMS Bologna, Italy), and MRI was performed using a 3T MR (Siemens Magnetom Skyra, Erlangen, Germany). USG reports and images, mammography images, and MRI were evaluated again. Kinetic curve measurement on dynamic contrast-enhanced series was performed. Also, diffusion coefficient measurements were made twice by a radiologist for each patient on the ADC maps ( $b$ values $=50,400$, $800 \mathrm{~s} / \mathrm{mm}^{2}$ ), and means of the measurements were used.

\section{Key Points}

- Although the most frequent diagnosis of IGM is in May and October in our patient population, there was no statistically significant difference.

- In more than half of IGM cases, US could provide an accurate prediagnosis approach of IGM.

- Besides MRI has a very limited role in discriminating malignancies from IGM, MRI enhancement kinetics may help in distinguishing this condition from malignancies.

\section{Statistical analysis}

The mean and standard deviation (SD) values of parameters were used to describe scale variables. Data are presented as mean \pm standard deviation. All measured frequencies regarding the seasonal variation were investigated using the Kruskal-Wallis test as to whether the recorded cases showed significant differences from each other. Results are detailed with descriptive characteristics and frequencies. Age and season categorical comparisons were analyzed using the Chisquare test. Statistical analyses were performed using IBM Statistical Package for the Social Sciences version 25 (IBM SPSS Corp.; Armonk, NY, USA). P values $<0.05$ were considered significant for the test results presented.

This study was approved by the Institutional Review Board Muğla Sıtkı Koçman University Ethics Committee (Number: 74, Date:02/06/2020). Informed consent was taken from all patients before the biopsy.

\section{Results}

Histopathologically, 37 patients with IGM with perilobular non-caseous granulomatous inflammation along with infiltration of neutrophils were evaluated. The average age of the 37 patients with IGM was $37.56 \pm 7.41$ (range, 24-59) years. A total of 29 (78.4\%) patients were aged $\leq 40$ years, and 35 (94.6\%) had a history of pregnancy. The date of the last delivery for eight patients was within the last 5 years. One patient was pregnant (43-year-old) and one patient was lactating (37-year-old) during the histopathologic diagnosis. A breast lump with pain was observed in all patients. Nipple retraction was observed in six patients (Figure 2). Fistula tract was observed in seven (18.9\%) patients during diagnosis. Two patients had galactorrhea. Radiologically, ipsilateral axillary lymph node enlargement was observed in 14 (37.8\%) patients (Table 1, 2).

Monthly frequencies were recorded as shown in Table 3. Although most cases were diagnosed in May and November, no significant difference was observed as compared with the other months. Seasonal categories were created with the months that belonged to the specific season (e.g. season 1 represents the months of December, January, and February), but no seasonal differences were observed $\mathrm{p}=0.392$. Age was categorized within two groups based on the mean, which was recorded as $37.88 \pm 7.19$ years. The seasonal differences were compared with age categories, but no statistically significant relationship was observed $\mathrm{p}=0.427$ (Table 4).

All patients underwent a USG evaluation in our center before the biopsy procedure. The sonographic results of the patients according to the BI-RADS lexicon were predominantly BI-RADS 3 and BI-RADS 4a (Table 5). In 21 (56.8\%) patients, the initial diagnosis of GM was noted in USG reports. Only one patient was reported as suspicious for inflammatory breast cancer and categorized as BIRADS 5 lesion. The distribution of lesions by quadrants is shown in Table 6. In our study group, only one quadrant involvement (48.6\%) was the most frequent involvement, followed by retroareolar space involvement (43.2\%). The most common USG features were hypoechoic mass or masses with tubular extensions (total 54\%) (Table 7, Figure 3).

Thirteen of the 37 patients had mammography. Mammography was performed in seven of the 25 patients aged under 40 (between 3038 , mean age 31.4) years, and six of 12 patients aged 40 years and over (age 44-59, mean age 49.3). The most common mammographic 

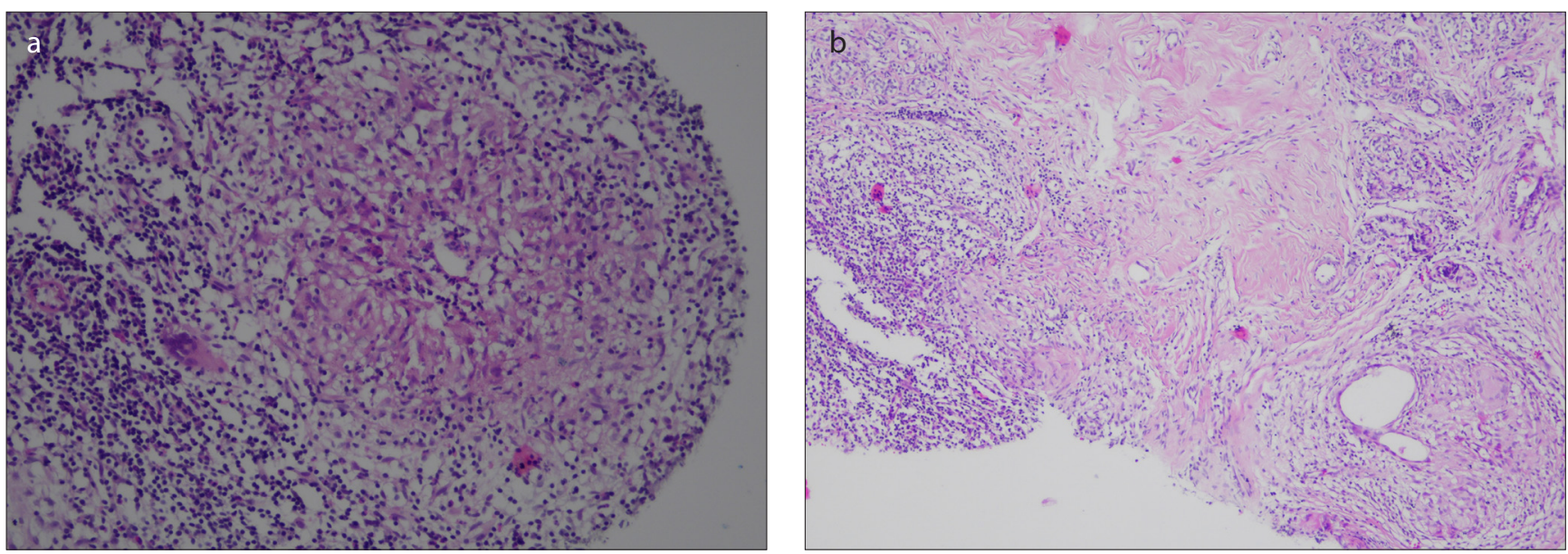

Figure 1. a, b. (a) x200 (b) x100 magnification hematoxylin and eosin stain (H\&E) demonstrating perilobular inflammation and granuloma formation in the background of diffuse lympho-histiocytic infiltration with giant cells

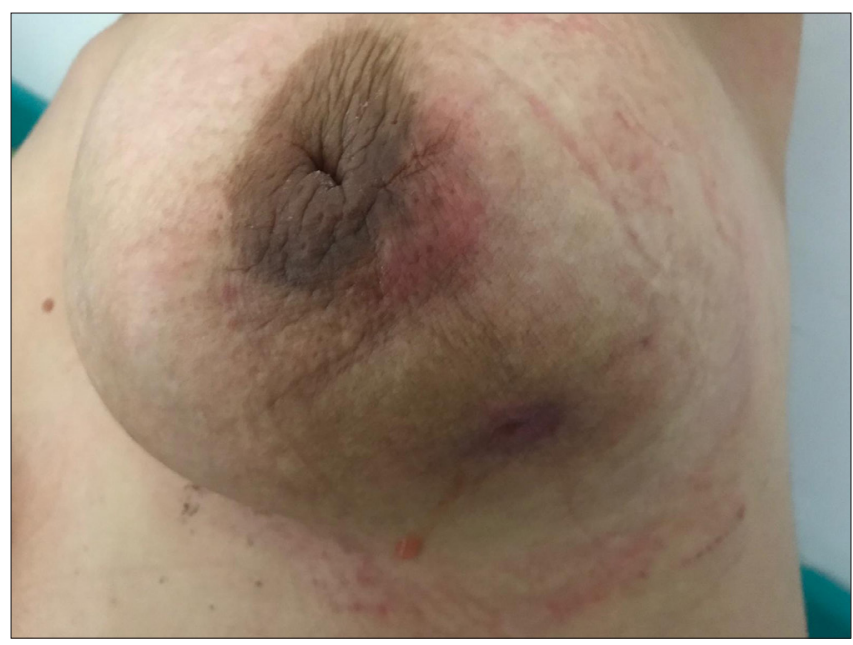

Figure 2. Unilateral breast erythema with retraction of the nipple and also draining sinus tract in the left breast of a 38-year-old-patient

\section{Table 1. Clinical characteristics of patients}

\begin{tabular}{lc} 
Characteristics & (n=37) \\
\hline Age, mean (range), years & $37.56 \pm 7.41(24-59)$ \\
$\leq 40$ years, $n(\%)$ & $29(78.4)$ \\
$>40$ years, $n(\%)$ & $8(21.6)$ \\
Pregnancy history, $n$ (\%) & $35(94.5)$ \\
Delivery, n (\%) & $34(91.8)$ \\
Number of births & $1.48(1-3)$ \\
Years postpartum & \\
$\leq 5, n(\%)$ & $8(22.9)$ \\
$>5, n(\%)$ & $27(77.1)$ \\
Lactation, $n(\%)$ & $1(2.7)$ \\
Abortion history, $n(\%)$ & $9(24.3)$
\end{tabular}

finding of IGM was asymmetrically increased density in our study population (Figure 4). Mammographic features were normal in one

\section{Table 2. Local manifestation of IGM}

$\begin{array}{lc}\text { Characteristics } & \text { IGM (n=37) } \\ \text { Side, } \mathbf{n}(\%) & 12(32.4) \\ \text { Right } & 25(67.5) \\ \text { Left } & 0 \\ \text { Bilateral } & 6(16.2) \\ \text { Nipple Retraction, } \mathbf{n}(\%) & 2(5.4) \\ \text { Galactorrhea, } n \text { (\%) } & \\ \text { The diameter of mass, (cm) } & 5.8 \\ \text { Mean } & 3.0-10.0 \\ \text { Range } & 37(100) \\ \text { Pain, } n \text { (\%) } & 14(37.8) \\ \text { Lymph node enlargement, } n \text { (\%) } & \\ \text { IGM: idiopathic granulomatous mastitis }\end{array}$

Table 3. Number of cases over the months

\begin{tabular}{lcc} 
Month & Number of cases & \% in overall \\
\hline 2 & 5 & 13.5 \\
3 & 5 & 13.5 \\
5 & 7 & 18.9 \\
6 & 1 & 2.7 \\
9 & 4 & 10.8 \\
10 & 3 & 8.1 \\
11 & 7 & 18.9 \\
12 & 5 & 13.5 \\
\hline
\end{tabular}

(7.7\%) patient, focal asymmetrically increased density in six (46.2\%), diffuse asymmetrically increased density in four (30.7\%), both diffuse asymmetrically increased density and parenchymal distortion in one (7.7\%), and mass in one (7.7\%) patient. 
Table 4. Number of cases by season and age group

\begin{tabular}{|c|c|c|c|}
\hline \multirow[b]{2}{*}{ Month group } & & \multicolumn{2}{|c|}{ Age group } \\
\hline & & $<37.88$ & $>37.88$ \\
\hline \multirow[t]{3}{*}{ Season $1(12,1,2)$} & Cases & 6 & 4 \\
\hline & $\%$ within month group & $60.00 \%$ & $40.00 \%$ \\
\hline & $\%$ within age group & $31.58 \%$ & $22.22 \%$ \\
\hline \multirow[t]{3}{*}{ Season $2(3,4,5)$} & Cases & 4 & 8 \\
\hline & $\%$ within month group & $33.30 \%$ & $66.70 \%$ \\
\hline & $\%$ within age group & $21.05 \%$ & $44.44 \%$ \\
\hline \multirow[t]{3}{*}{ Season $3(6,7,8)$} & Cases & 1 & 0 \\
\hline & $\%$ within month group & $100.00 \%$ & $0.00 \%$ \\
\hline & $\%$ within age group & $5.26 \%$ & $0.00 \%$ \\
\hline \multirow[t]{3}{*}{ Season $4(9,10,11)$} & Cases & 8 & 6 \\
\hline & $\%$ within month group & $57.14 \%$ & $42.86 \%$ \\
\hline & $\%$ within age group & $42.10 \%$ & $33.33 \%$ \\
\hline
\end{tabular}

Table 5. BI-RADS categorization of the lesions

\begin{tabular}{|lcc|}
\hline BI-RADS category & $\mathbf{n}$ & \% \\
\hline 3 & 14 & 38.7 \\
$4 \mathrm{~A}$ & 15 & 40.5 \\
$4 \mathrm{~B}$ & 4 & 10.8 \\
$4 \mathrm{C}$ & 3 & 8.1 \\
5 & 1 & 2.7 \\
\hline BI-RADS: Breast Imaging-Reporting and Data System & \\
\hline
\end{tabular}

Table 6. Distribution of the lesions due to quadrants of the breast

\begin{tabular}{lcc|}
\hline Quadrant & $\mathbf{n}$ & \% \\
\hline $\mathrm{R}$ & 1 & 2.7 \\
$1 \mathrm{Q}$ & 18 & 48.6 \\
$1 \mathrm{Q}+\mathrm{R}$ & 5 & 13.5 \\
$2 \mathrm{Q}$ & 3 & 8.1 \\
$2 \mathrm{Q}+\mathrm{R}$ & 5 & 13.5 \\
$3 \mathrm{Q}+\mathrm{R}$ & 3 & 8.1 \\
$4 \mathrm{Q}+\mathrm{R}$ & 2 & 5.4 \\
\hline Q: quadrant; R: retroareolar region & \\
\hline
\end{tabular}

Breast MRI was performed in 10 patients; non-mass enhancement (NME) was observed in five of these patients, mass was found in three, and both NME and mass were detected in two patients (Table 8). In kinetic measurements, one lesion showed a type 2 curve, and nine lesions had a type 1 curve (Figure 5). Diffusion-weighted imaging was performed in six patients and all lesions showed diffusion restriction (Figure 6). The mean

\section{Table 7. Sonographic features of IGM}

\begin{tabular}{|c|c|c|}
\hline Sonographic features & $\mathbf{n}$ & $\%$ \\
\hline $\begin{array}{l}\text { Multiple irregular hypoechoic } \\
\text { masses and collections with tubular } \\
\text { connection with internal echoes }\end{array}$ & 11 & 29.7 \\
\hline $\begin{array}{l}\text { A large irregular hypoechoic } \\
\text { parallel mass with tubular extensions }\end{array}$ & 9 & 24.3 \\
\hline $\begin{array}{l}\text { Focal hypoechoic heterogeneity } \\
\text { with indistinct border }\end{array}$ & 6 & 16.2 \\
\hline $\begin{array}{l}\text { An irregular hypoechoic mass with } \\
\text { internal echoes (+signs of inflammation } \\
\text { around the mass) }\end{array}$ & $\begin{array}{l}3(+2) \\
\text { Total } 5\end{array}$ & 13.5 \\
\hline $\begin{array}{l}\text { Collection areas with low-level internal } \\
\text { echoes consistent with abscesses }\end{array}$ & 4 & 10.8 \\
\hline $\begin{array}{l}\text { The hypoechoic heterogeneous masses } \\
\text { within ducts and inflammation signs around } \\
\text { the ducts }\end{array}$ & 2 & 5.4 \\
\hline
\end{tabular}

There was no follow-up information of $22(59.4 \%)$ patients in our center. The follow-up time of 15 patients with follow-up data in our center ranged between one and 26 months and the average follow-up period was 11.8 months. In the radiologic follow-up, complete recovery was observed in six $(40 \%)$ patients, regression in four $(26.6 \%)$, progression in three $(20 \%)$, recurrence after recovery in one $(6.7 \%)$, and one $(6.7 \%)$ patient's USG findings were stable. Surgical excision was performed in two patients because of an insufficient response to medical treatment.

\section{Discussion and Conclusion}

IGM is considered as a rare chronic non-specific inflammatory lesion of the breast (1). Histopathologically, it is characterized by the presence 

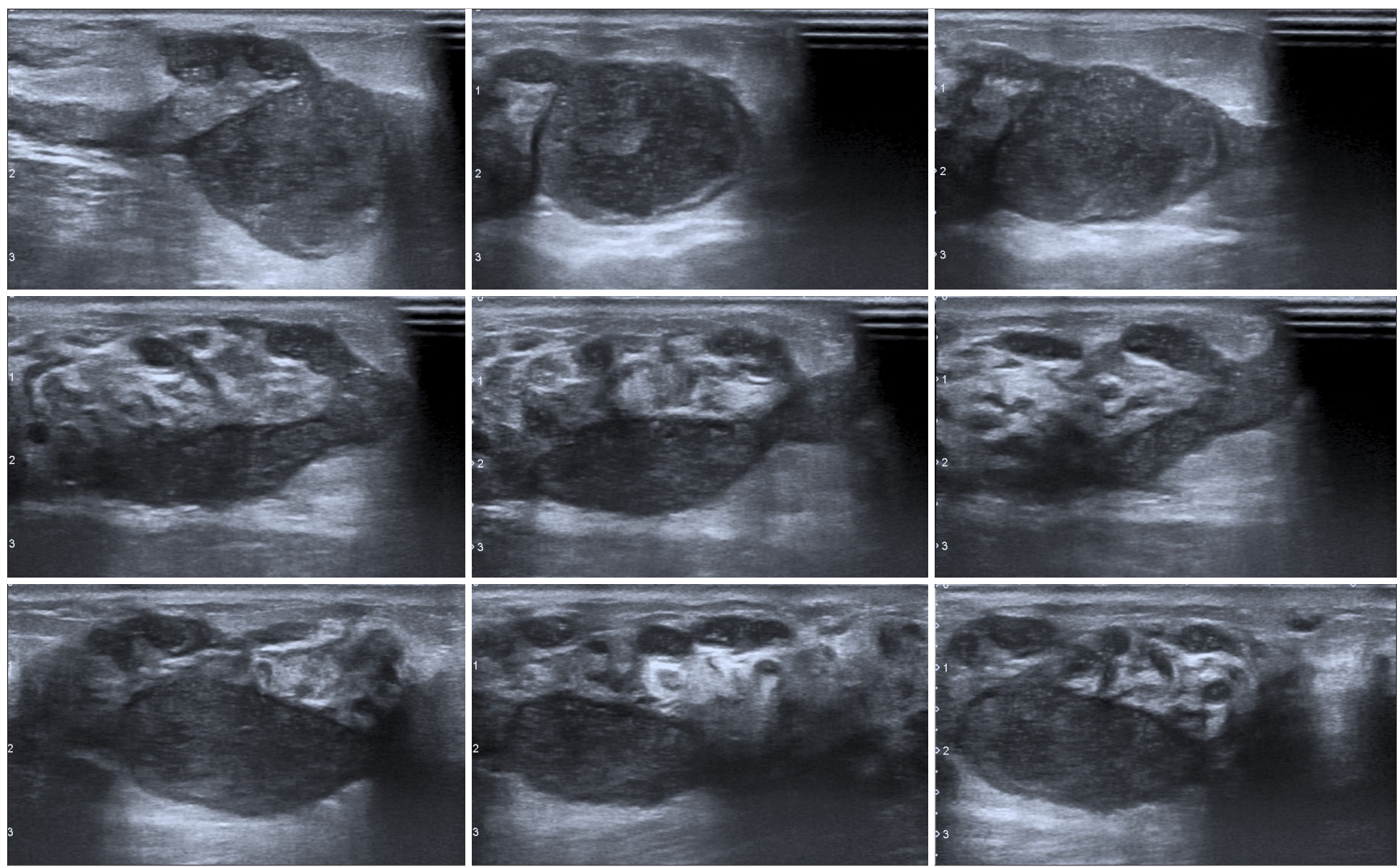

Figure 3. Ultrasound images of a patient with hypoechoic masses containing internal echoes with tubular extensions

Table 8. MRI features of IGM ( 5 cases shows nonmass enhancement (NME), 3 cases mass and, 2 cases both NME and mass)

\begin{tabular}{lc} 
MRI lesion type and imaging feature & $\mathbf{n}$ \\
\hline Non-mass enhancement & 7 \\
Patterns: & \\
Clustered ring & 3 \\
Heterogeneous & 3 \\
Clumped & 1 \\
Distribution: & \\
Regional & 6 \\
Diffuse & 1 \\
Mass & 5 \\
Shape: & \\
Round & 3 \\
Irregular & 2 \\
Margin: & \\
Circumscribed & 1 \\
Irregular & 4 \\
\hline IGM: idiopathic granulomatous mastitis; MRI: magnetic resonance imaging
\end{tabular}

of epithelioid and multinucleated giant cell non-caseating granulomas accompanied by neutrophils around the lobules (13). Although it has been reported that the age of patients with IGM may range from 11 to 80 years (14), the high-risk group is women, aged between 30 and 40 years (15). In our study population, eight patients were aged over 40 years and five patients were aged under 30 years, the mean age of the study population was $37.56 \pm 7.41$ years, correlating with the literature.

The etiology and pathogenesis of IGM remain unclear. An association with pregnancy, lactation, a locally autoimmune process, infection, hyperprolactinemia, and chemical reaction induced by oral contraceptive pills have been reported in previously published articles $(10,11)$. After reviewing the literature, it is revealed that the majority of patients are of Mediterranean (Turkey and Jordan) and Asian (Arabia, China, and Malaysia) origin (4). Although no obvious ethnic predisposition has been previously reported, the prevalence of IGM in specific ethnic populations has been mentioned in several reports $(5,16)$. Previous studies supported the conclusion that patients with IGM were usually parous women with a recent history of pregnancy and delivery $(9$, 14). In our study group, $94.6 \%$ of patients had a history of pregnancy and one was pregnant at the time of diagnosis. It has been published that extravasation lactational secretions may spontaneously produce a granulomatous inflammatory response $(5,17)$. Also, that high serum prolactin levels and subsequent overexcitation and lactation change can potentially cause IGM (18). In our study population, two patients have galactorrhea and one patient was lactating at the time of diagnosis.

The most common clinical symptoms of IGM include erythema, edema, variable sized-sensitive-palpable unilateral breast mass, nipple retraction, ulceration, discharge, and axillary lymphadenopathy (19). The presence of a fistula tract in patients is an important clinical clue for the referral diagnosis of IGM $(20,21)$. In our study, fistula was present in approximately $20 \%$ of patients. In some studies, the fistula 


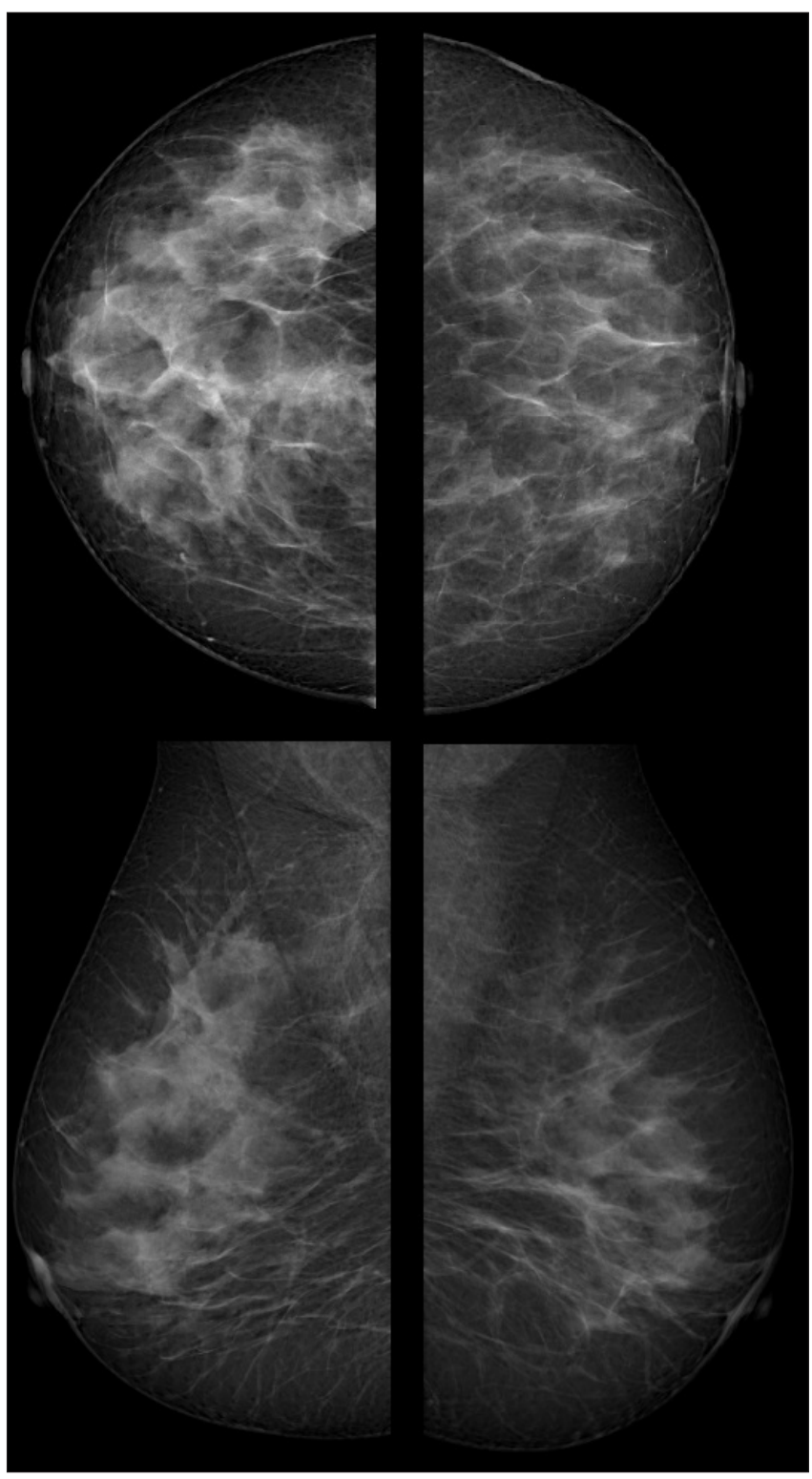

Figure 4. In the mammography of a patient asymmetrically increased density in upper quadrant central portion of the right breast

presentation was found as $30-50 \%(8,9,22)$. In our study group, axillary lymph node enlargement was observed in $37.8 \%$ of patients, and studies have shown unilateral lymph node involvement as between $20-60 \%$ in IGM $(9,23)$.

To our knowledge, there is no article discussing seasonal frequency in IGM. Most of our patients presented to the hospital and biopsied in May and November $(n=14,37.8 \%)$, but there was no significant difference when compared with the other months. Of these two months when the most frequent cases were seen, May corresponds to the end of spring, and November to the end of autumn. Most of the patients presented to hospital in autumn and spring. Only one patient's diagnosis was in summer. Although there was no statistically significant difference between the months, the distribution of months may show us seasonal proximity in this condition and this feature may help to understand the etiopathogenesis of IGM. Our population was very limited, so to investigate the seasonal relationship in this condition there is a need for studies with much larger numbers of patients. We think that the evaluation of the onset of
In our study, in the USG reports of $21(56.8 \%)$ patients, an initial diagnosis of GM was noted. This finding shows that in more than half of IGM cases, we can only provide an accurate pre-diagnosis approach with the typical USG appearance features. In our study, the reason for the high rates of accurate pre-diagnosis of IGM may be that most of the cases apply to our clinic when the lesions are being prominent and typical forms. If typical sonographic findings of GM such as masses containing internal echoes connecting each other by tubular extension and tracts extending to the skin, the pre-diagnosis can be easily performed. However, GM has wide sonographic appearances that cause a radiologic dilemma in diagnosis (23). In our study, $21.6 \%$ of our patients were categorized as BI-RADS $4 \mathrm{~B}, 4 \mathrm{C}$, or 5 , which show that there was a $20 \%$ of the patient group with which we had difficulty in pre-diagnosis. Similar to previous literature, in our study, the most common USG features were hypoechoic mass or masses with tubular extensions (54\%), which allows us to consider the preliminary diagnosis of granulomatous mastitis $(9,24,25)$.

In our cases, single quadrant involvement (48.6\%) was the most frequent involvement, followed by retroareoler space involvement (43.2\%). In a study that evaluated 30 patients, lesion extension to the retroareoler space was found in 50\% of patients (9). In another study with 37 patients, retroareoler involvement was found in $66.7 \%$ of patients, and all-quadrant involvement $(38.1 \%)$ was the most frequent (22). In this study, the reason that the retroareoler area involvement and 3 and more quadrant involvement was more frequent than our study may be due to the population of the other study comprising patients who had MRI for further investigations. It may also be due to the better determination of the extent of lesions with MRI. Retroareoler involvement may be related to the process and progression of lesions. In a study, it was shown that patients with retroareoler space involvement had poorer treatment success (26). Therefore, it may be clinically important to document whether retroareoler site involvement is present.

Although mammographic sensitivity is low due to the young age group having a dense breast pattern, the most common mammographic finding in our study was asymmetrically increased density (10/13). In previous studies, almost half of the mammograms were negative and the most common finding was an asymmetric density, which was a nonspecific finding $(9,21,25,27)$.

There are a few studies about the MRI features of IGM, and this modality has a very limited role in discriminating malignancies from IGM in the initial diagnosis of this condition. MRI findings have a wide spectrum $(25,28,29)$. Although NME was seen in all MRIs in one study, in our study NME was observed in $70 \%$ of MRIs (28). Aslan et al. (29) showed NME in $92.3 \%$ of patients, and Yilmaz et al. (22) reported NME in $55 \%$ of patients.

One of the most striking findings of this condition in MRI was that the kinetic curve was seen as a type 1 curve in most cases. In contrast to our findings, Chu et al. (28) found wash-out in all of lesions. Yilmaz et al. (22) reported that $64 \%$ of patients had type 1 enhancement, and $36 \%$ of patients had type 2 enhancement. In MRI, enhancement kinetics may help in distinguishing this condition from malignancies.

Although IGM is a benign condition, in our study, all lesions showed diffusion restriction, similar to a study by Aslan et al. (29) However, in our study, the mean ADC values were found lower than in that study. In a study in terms of ADC values, there was no difference in IGM 

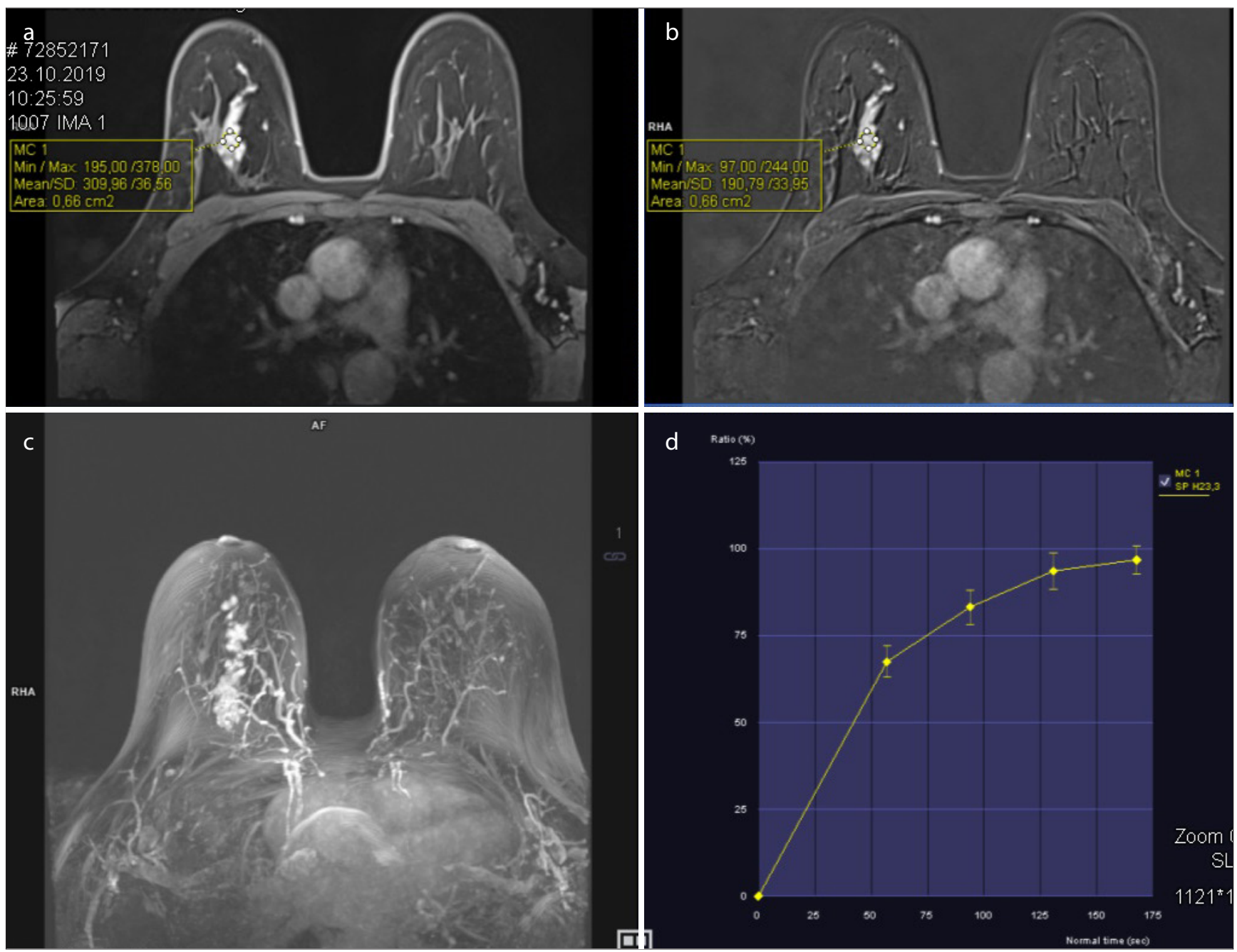

Figure 5. a-d. Non-mass enhancement on the right breast with type 1 kinetic curve
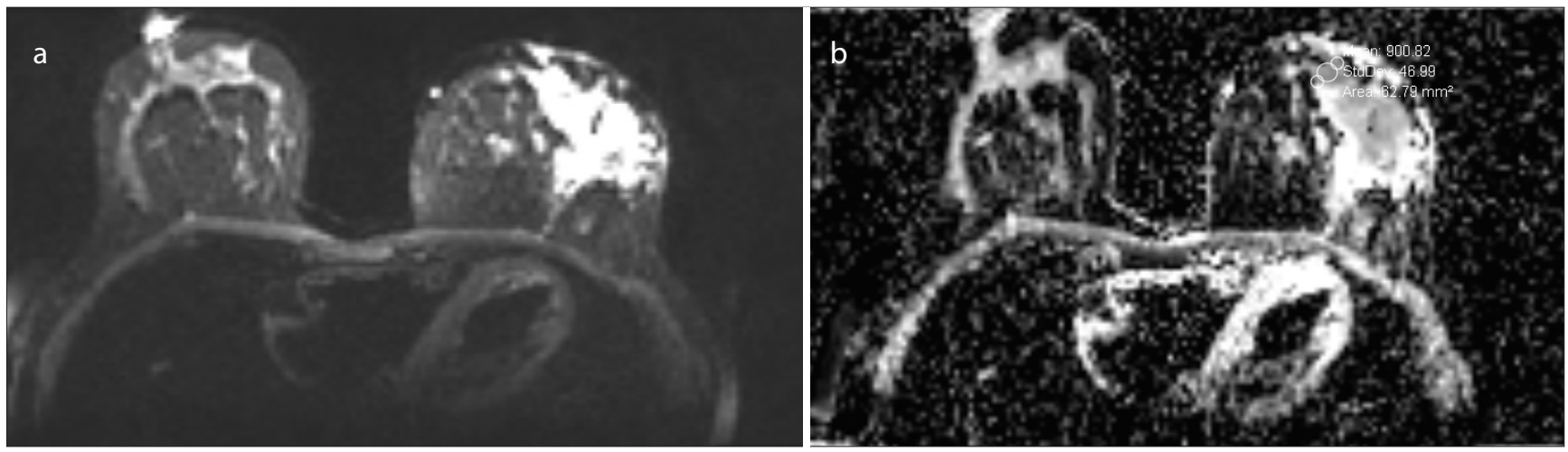

Figure 6. a, b. Diffusion restriction (ADC value: $0.90 \mathrm{~mm}^{2} / \mathrm{s} .10^{-3}$ ) of granulomatous mastitis on diffusion-weighted imaging

and malignancies (25). In contrast to that study, a recent study demonstrated that in non-mass enhancement without rim-enhancement, using texture analysis in diffusion images was useful in the differentiation of IGM from malignancies (30). In a study evaluating mastitis, it was shown that ADC values could be used to classify mastitis subtypes (31). There are conflicting MRI findings in different studies and in our study, MRI findings were non-specific, similar to the literature.

Besides the clinical features, radiologic findings of IGM may also be confused with malignant pathologies of the breast. The disease must be diagnosed through a pathologic evaluation. Fine needle aspiration is not satisfactory in distinguishing malignant and other benign inflammatory disorders. A core biopsy should be preferred for this purpose $(5,7,23)$. In our patient group, all patients were diagnosed after having a core needle biopsy. A diagnostic excisional biopsy is not preferred due to substantial scratching, loss of breast symmetry, breast deformity, and the possibility of unhealed ulcers or sinus tract formation $(7,32)$.

Treatment of IGM should be initiated after the exclusion of infective causes. It involves non-surgical management including surveillance, 
corticosteroids, and other immunosuppressive agents including methotrexate or azathioprine, in cases of refractory disease. If no regression is observed during surveillance or disease becomes symptomatic, corticosteroids should be initiated, with gradual tapering of the dose. In cases of recurrent disease, in addition to all non-surgical management options, surgical excision can also be considered as an option. Although complete response can be achieved after appropriate application of treatment strategies, recurrence is common, and patients should be closely followed $(33,34)$. Surgery was performed in two patients after medical treatment due to inadequate treatment response. Only $40.6 \%$ of the patients had radiologic follow-up records in our center, and the low rate of follow-up may be because the majority of this patient population was aged under 40 years. In this condition, presenting with pain, deformation and fistulas in the breast, follow-up and treatment compliance may be low due to the chronic course of the illness. The rate of recurrence and progression in patients who had follow-up information was $26.6 \%$.

The main limitation of the study is the low number of patients. Another important limitation of the current study is that there are no data on how long after symptoms developed in patients the biopsy was performed. The date of the biopsy was accepted as the date of illness. Patients may have presented at different periods after symptoms developed, and so, the time between symptoms and biopsy may vary from case to case. For this reason, considering the date of biopsy as the date of disease in our study may have caused some errors and bias. Studies with a larger series focusing on the onset of symptoms may shed light on the IGM season relationship.

In conclusion, IGM is a rare chronic non-specific inflammatory lesion of the breast, which can be confused with benign and malignant breast diseases in both clinical and radiologic aspects. To understand the etiology of this condition better, the seasonal connection needs to be evaluated in larger patient groups.

Ethics Committee Approval: Ethics committee approval was received for this study from the ethics committee of Muğla Sttkı Koçman University (Number: 74, Date:02/06/2020).

Informed Consent: Written informed consent was obtained from patients before the biopsy.

Peer-review: Externally peer-reviewed.

Author Contributions: Concept - L.T., F.D.E.; Design - F.D.E., L.T.; Supervision - F.D.E.; Resources - L.T., F.D.E.; Materials - L.T., F.D.E.; Data Collection and/or Processing - L.T., F.D.E.; Analysis and/or Interpretation F.D.E., L.T.; Literature Search - F.D.E., L.T.; Writing Manuscript - F.D.E., L.T.; Critical Review - F.D.E., L.T.

Conflict of Interest: The authors have no conflicts of interest to declare.

Financial Disclosure: The authors declared that this study has received no financial support.

\section{References}

1. Sheybani F, Sarvghad M, Naderi HR, Gharib M. Treatment for and clinical characteristics of granulomatous mastitis. Obstet Gynecol 2015; 125 : 801-807. (PMID: 25751209) [Crossref]

2. Gurleyik G, Aktekin A, Aker F, Karagulle H, Saglamc A. Medical and surgical treatment of idiopathic granulomatous lobular mastitis: A benign inflammatory disease mimicking invasive carcinoma. J Breast Cancer 2012;15: 119-123. (PMID: 22493638) [Crossref]
3. Galea MH, Robertson JF, Ellis IO, Elston CW, Blamey RW. Granulomatous lobular mastitis. Aust N Z J Surg 1989; 59: 547-550. (PMID: 2665711) [Crossref]

4. Baslaim MM, Khayat HA, Al-Amoudi SA. Idiopathic granulomatous mastitis: A heterogeneous disease with variable clinical presentation. World J Surg 2007; 31: 1677-1681. (PMID: 17541683) [Crossref]

5. Al-Khaffaf B, Knox F, Bundred NJ. Idiopathic granulomatous mastitis: A 25-year experience. J Am Coll Surg 2008; 206: 269-273. (PMID: 18222379) [Crossref]

6. Kiyak G, Dumlu EG, Kilinc I, Tokaç M, Akbaba S, Gurer A, Kilic M. Management of idiopathic granulomatous mastitis: dilemmas in diagnosis and treatment. BMC Surg 2014; 14: 66. (PMID: 25189179) [Crossref]

7. Turull CW, Nanyes JE, Quintero CJ, Alizai H, Mais DD, Kist KA, Dornbluth NC. Idiopathic granulomatous mastitis: manifestations at multimodality imaging and pitfalls. RadioGraphics. 2018; 38: 330-356. (PMID: 29528819) [Crossref]

8. Dursun M, Yilmaz S, Yahyayev A, Salmaslioglu A, Yavuz E, Igci A, Acunas G, Tunacı M. (2012) Multimodality imaging features of idiopathic granulomatous mastitis: outcome of 12 years of experience. Radiol Med 2012; 117: 529-538. (PMID: 22020426) [Crossref]

9. Yildiz S, Aralasmak A, Kadioglu H, Toprak H, Yetis H, Gucin Z, Kocakoc E. Radiologic findings of idiopathic granulomatous mastitis. Med Ultrason 2015; 17: 39-44. (PMID: 25745656) [Crossref]

10. Altintoprak F, Kivilcim T, Ozkan OV. Aetiology of idiopathic granulomatous mastitis World J Clin Cases 2014; 2: 852-858. (PMID: 25516860) [Crossref]

11. Uysal E, Soran A, Sezgin E. Factors related to recurrence of idiopathic granulomatous mastitis: what do we learn from a multicentre study? ANZ J Surg 2018; 88: 635-639. (PMID: 28749045) [Crossref]

12. American College of Radiology. Breast Imaging Reporting \& Data System, BI-RADS: Mammography. 5th ed. Reston, VA: 2013.

13. Tuli R, O'Hara BJ, Hines J, Rosenberg AL. Idiopathic granulo-matous mastitis masquerading as carcinoma of the breast: A case report and review of the literature. Int Semin Surg Oncol 2007; 4: 21. (PMID: 17662130) [Crossref]

14. Bani-Hani KE, Yaghan RJ, Matalka II, Shatnawi NJ. Idiopathic granulomatous mastitis: Time to avoid unnecessary mastectomies. Breast J 2004; 10: 318-322. (PMID: 15239790) [Crossref]

15. Pereira FA, Mudgil AV, Macias ES, Karsif K. Idiopathic granulomatous lobular mastitis. Int J Dermatol 2012; 51: 142-151. (PMID: 22250621) [Crossref]

16. Centers for Disease Control and Prevention (CDC). Idiopathic granulomatous mastitis in Hispanic women -Indiana, 2006-2008. MMWR Morb Mortal Wkly Rep 2009; 58: 1317-1321. (PMID: 19959984)

17. Marriott DA, Russell J, Grebosky J, Wallace AM, Joste N, Royce ME. Idiopathic granulomatous lobular mastitis masquerading as a breast abscess and breast carcinoma. Am J Clin Oncol 2007; 30: 564-565. (PMID: 17921721) [Crossref]

18. Cserni G, Szajki K. Granulomatous lobular mastitis following drug-induced galactorrhea and blunt trauma. Breast J 1999; 5: 398-403. (PMID: 11348321) [Crossref]

19. Ocal K, Dag A, Turkmenoglu O, Kara T, Seyit H, Konca K. Granulomatous mastitis: clinical, pathological features, and management. Breast J 2010; 16: 176-182. (PMID: 20030652) [Crossref]

20. Almasad, Jamal K. Mammary duct fistulae: classification and management. ANZ J Surg 2006, 76: 149-152. (PMID: 16626355) [Crossref]

21. Ozel L, Unal A, Unal E, Kara M, Erdoğdu E, Krand O, Güneş P, Karagül H, Demiral S, Titiz MI. Granulomatous mastitis: is it an autoimmune disease? Diagnostic and therapeutic dilemmas. Surg Today 2012; 42: 729733. (PMID: 22068681) [Crossref]

22. Yilmaz R, Demir AA, Kaplan A, Sahin D, Ozkurt E, Dursun M, Acunas $G$. Magnetic resonance imaging features of idiopathic granulomatous mastitis: is there any contribution of diffusion-weighted imaging in the differential diagnosis?. Radiol Med 2016; 121: 857-866. (PMID: 27406630) [Crossref] 
23. Sripathi S, Ayachit A, Bala A, Kadavigere R, Kumar S. Idiopathic granulomatous mastitis: a diagnostic dilemma for the breast radiologist. Insights Imaging 2016; 7: 523-529. (PMID: 27164916) [Crossref]

24. Engin G, Acunaş G, Acunaş B. Granulomatous mastitis: gray-scale and color Doppler sonographic findings. J Clin Ultrasound 1999; 27: 101106. (PMID: 10064406) [Crossref]

25. Yilmaz E, Lebe B, Usal C, Balci P. Mammographic and sonographic findings in the diagnosis of idiopathic granulomatous mastitis. Eur Radiol 2001; 11: 2236-2240. (PMID: 11702165) [Crossref]

26. Altunkeser A, Arslan FZ, Eryılmaz MA. Magnetic resonance imaging findings of idiopathic granulomatous mastitis: can it be an indirect sign of treatment success or fail?. BMC Med Imaging 2019; 19: 94. (PMID: 31842782) [Crossref]

27. Memis A, Bilgen I, Ustun EE, Ozdemir N, Erhan Y, Kapkac M. Granulomatous mastitis: imaging findings with histopathologic correlation. Clin Radiol 2002; 57: 1001-1006. (PMID: 12409111) [Crossref]

28. Chu AN, Seiler SJ, Hayes JC, Wooldridge R, Porembka JH. Magnetic resonance imaging characteristics of granulomatous mastitis. Clin Imaging 2017; 43: 199-201. (PMID: 28364724) [Crossref]

29. Aslan H, Pourbagher A, Colakoglu T. Idiopathic granulomatous mastitis: magnetic resonance imaging findings with diffusion MRI. Acta Radiol 2016; 57: 796-801. (PMID: 2650879) [Crossref]
30. Zhao Q, Xie T, Fu C, Chen L, Bai Q, Grimm R, Peng W, Wang S. Differentiation between idiopathic granulomatous mastitis and invasive breast carcinoma, both presenting with non-mass enhancement without rimenhanced masses: The value of whole-lesion histogram and texture analysis using apparent diffusion coefficient. Eur J Radiol 2020; 123: 108782. (PMID: 31864142) [Crossref]

31. Zhang L, Hu J, Guys N, Meng J, Chu J, Zhang W, Liu A, Wang S, Song Q. Diffusion-weighted imaging in relation to morphology on dynamic contrast enhancement MRI: the diagnostic value of characterizing nonpuerperal mastitis. Eur Radiol 2018; 28: 992-999. (PMID: 28956122) [Crossref]

32. Kok KY, Telisinghe PU. Granulomatous mastitis: presentation, treatment and outcome in 43 patients. Surgeon 2010; 8: 197-201. (PMID: 20569938) [Crossref]

33. Freeman CM, Xia BT, Wilson GC, Lewis JD, Khan S, Lee SJ, Lower EE, Edwards MJ, Shaughnessy EA. Idiopathic granulomatous mastitis: A diagnostic and therapeutic challenge. Am J Surg 2017; 214: 701-706. (PMID: 28739122) [Crossref]

34. Atak T, Sagiroglu J, Eren T, Alimoglu O. Strategies to treat idiopathic granulomatous mastitis: retrospective analysis of 40 patients. Breast Dis 2015; 35: 19-24. (PMID: 24989362) [Crossref] 